\title{
CARLOS LUIS FALLAS: DIFUSIÓN, COMERCIALIZACIÓN Y ESTUDIO DE SUS OBRAS. UNA CONTRIBUCIÓN DOCUMENTAL ${ }^{1}$
}

\section{CARLOS LUIS FALLAS: DISTRIBUTION, MARKETING AND STUDIES OF HIS BOOKS. A DOCUMENTARY CONTRIBUTION}

\author{
Iván Molina Jiménez*
}

\begin{abstract}
RESUMEN
El propósito principal de este artículo es analizar la difusión, comercialización y estudio de las obras del escritor comunista costarricense, Carlos Luis Fallas Sibaja (1909-1966). La base de este artículo son dos anexos: el primero, recopila los principales datos bibliográficos sobre sus novelas y cuentos; el segundo, muestra los estudios académicos que se refieren a tales libros. Se incluye, además, una detallada cronología que recupera los hechos fundamentales de la vida política y literaria del escritor mencionado.
\end{abstract}

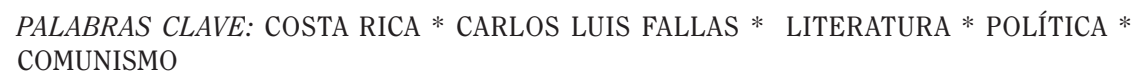

1 La preparación de este artículo se realizó en el Centro de Investigación en Identidad y Cultura Latinoamericanas (CIICLA) y fue financiado por la Vicerrectoría de Investigación de la Universidad de Costa Rica. Agradezco la colaboración de diversas personas e instituciones en la localización de algunos de los materiales y en la revisión de las referencias bibliográficas consignadas en los anexos 1, 2 y 3, en especial a María Elena Céspedes Rodríguez, David Díaz Arias, Lucía Jiménez Gómez, Lowell Gudmundson, Sherry Gapper, Héctor Solano Chavarría, Rodolfo González Ulloa, Maribel Santamaría, Adrian Johnson, Juan Durán Luzio, Bobray J. Bordelon, Petra Metzelthin, Kroot
Liivak, Mariannick Guennec, Judit Tomcsányi, Jayne Finlay, Elizabeth Mahoney, Nicole Ruggle, Peggy Kolberg, Silvia Tecchio, Valéria Szeli, Etleva Domi, Miki Goral, Christine Walters, Ramón Figueroa, Mayra Achío Tacsan, Benedicto Víquez Guzmán, Marlies Hertig, Steve Mendoza, Leslie Chinchilla Noguera, Daniel Bonilla Matamoros, Richard Phillips y Nancy McClements. El suscrito, sin embargo, es el único responsable de los errores $y$ omisiones contenidos en el presente artículo.

* Escuela de Historia de la Universidad de Costa Rica. ivan.molina@ucr.ac.cr 


\section{ABSTRACT}

This article analyzes the distribution, marketing and study of the books of the Costa Rican Communist writer, Carlos Luis Fallas Sibaja (1909-1966). The main sources for this research are two annexes: the first, compiles bibliographic data on his novels and short stories and the second, the scholarly works referred to such books. The article also includes a detailed chronology that retrieves the basic facts of the political and literary life of Fallas.

KEYWORDS: COSTA RICA * CARLOS LUIS FALLAS * LITERATURE * POLITICS * COMMUNISM

El escritor Carlos Luis Fallas Sibaja (1909-1966) es una de las principales figuras de la literatura costarricense.Tras una infancia e inicios de una adolescencia en que terminó la escuela y cursó los dos primeros años de colegio - un logro educativo ajeno a la mayoría de los niños y jóvenes de su época-, en 1925 se trasladó al Caribe para laborar en las actividades bananeras dominadas por la United Fruit Company. La permanencia en esa área se prolongó por más de un quinquenio. En 1931, regresó a la ciudad de Alajuela, de donde era oriunda la familia de su madre y aprendió el oficio de zapatero ${ }^{2}$. La fundación del Partido Comunista de Costa Rica (PCCR), en junio de ese año ${ }^{3}$, le ofreció una opción para canalizar sus inquietudes políticas y sociales, en un país profundamente afectado por la crisis económica mundial de $1930^{4}$.

El ascenso de Fallas dentro del PCCR fue extremadamente rápido, a lo cual contribuyó su liderazgo entre los trabajadores, proceso que culminó en el importante papel que jugó en la huelga bananera de agosto-septiembre de

$2 \quad$ Arroyo, Víctor Manuel. Carlos Luis Fallas. San José: Ministerio de Cultura, Juventud y Deportes, 1973; Aguilar Hernández, Marielos. Carlos Luis Fallas: su época y sus luchas. San José: Editorial Porvenir, 1983.

Botey Sobrado, Ana María y Cisneros Castro, Rodolfo. La crisis de 1929 y la fundación del Partido Comunista de Costa Rica. San José: Editorial Costa Rica, 1984.

Bulmer-Thomas, Víctor. La economía política de Centroamérica desde 1920. San José. Banco Centroamericano de Integración Económica, 1989: 61-86.
$1934^{5}$. La colaboración con el periódico comunista Trabajo, se convirtió en la base para que profundizara la formación intelectual lograda durante su etapa de estudiante y gracias también a su afición por la lectura ${ }^{6}$. Los resultados de estos afanes se materializaron en artículos, folletos y libros; de estos últimos, los más conocidos son sus obras de ficción, algunas de las cuales alcanzaron una decisiva difusión internacional al ser traducidas a diversos idiomas: Mamita Yunai (1941), Gentes y gentecillas (1947), Marcos Ramírez (1952), Mi madrina (1954) y Tres cuentos (1967)

El propósito principal de este artículo es ofrecer una versión actualizada y revisada de los datos bibliográficos de todos los textos escritos por Fallas que fueron publicados como libros y folletos (Anexo 1), los principales estudios y crónicas referidos a él y a su obra (Anexo 2) y los eventos más significativos de su vida política $y$ literaria (Anexo 3). La conveniencia de realizar este trabajo se explica porque todavía circula información errónea o incompleta acerca de

$5 \quad$ Sibaja Barrantes, Emel. "Ideología y protesta popular: la huelga bananera de 1934 en Costa Rica". [Tesis de Licenciatura en Historia] Universidad Nacional, 1983. Acuña Ortega, Víctor Hugo.La huelga bananera de 1934. San José: CENAP-CEPAS, 1984

6 Molina Jiménez, Iván. "Un pasado comunista por considerar. Carmen Lyra y Carlos Luis Fallas en la década de 1930". Lyra, Carmen y Fallas, Carlos Luis. Ensayos políticos. San José. Editorial de la Universidad de Costa Rica, 2000: 48.

7 Sánchez Mora, Alexánder. "Las múltiples lenguas de Calufa”. Káñina. Revista de Artes y Letras de la Universidad de Costa Rica XXXIV (2). San José, 2010: 43-46. 
este escritor y de su producción narrativa $y$ ensayística. La elaboración de un listado de sus artículos periodísticos y de las opiniones, noticias y reportajes que la prensa dio a conocer sobre su persona y sus actividades, es una tarea ya iniciada ${ }^{8}$, que urge profundizar a futuro.

\section{EDICIONES EXTRANJERAS}

La importante difusión internacional lograda por las obras literarias de Fallas se sintetiza en el Cuadro 1, el cual muestra que la base de ese proceso fueron sus novelas Mamita Yunai y Marcos Ramírez. La mayoría de las versiones publicadas en idiomas distintos del español, circularon en países socialistas, aunque ambos libros también fueron editados en francés, una lengua de amplia proyección internacional ${ }^{9}$. El motivo por el cual no se realizaron traducciones al inglés es un tema que debe ser investigado más a fondo, con base en un estudio que, aparte de considerar la influencia que tuvieron la intensificación de la guerra fría $y$ el ascenso del macartismo, examine los vínculos y comunicaciones entre los comunistas de Costa Rica y sus contrapartes de Estados Unidos y Gran Bretaña.

\begin{tabular}{|c|c|c|c|c|c|}
\hline - EDICION & S FUERA DE COSTA & $\begin{array}{r}\text { CUADR } \\
\text { CA DE LAS PRI }\end{array}$ & $\begin{array}{l}1 \\
\text { CIPALES OI }\end{array}$ & AS DE FALLAS (1949 & $86)^{*}$ \\
\hline PAÍS & MAMITA YUNAI & $\begin{array}{c}\text { GENTES Y } \\
\text { GENTECILLAS }\end{array}$ & $\begin{array}{l}\text { MARCOS } \\
\text { RAMÍREZ }\end{array}$ & MI MADRINA & $\begin{array}{c}\text { TRES } \\
\text { CUENTOS** }\end{array}$ \\
\hline Albania & 1971 & & & & \\
\hline Alemania oriental & 1954,1961 & & 1955 & & \\
\hline Argentina & 1955,1956 & & 1957 & & \\
\hline Bulgaria & 1957 & & 1968 & & \\
\hline Checoeslovaquia & 1953 & & 1977 & & \\
\hline Chile & 1949,1972 & & & & \\
\hline China & 1958 & & & & \\
\hline Cuba & $1960,1961,1961,1975$ & 1987 & & & \\
\hline El Salvador & & & & 1986, 1989, 1993, 1995 & 1999 \\
\hline Eslovaquia*** & 1954 & & 1960,1977 & & \\
\hline España & 1976 & & & & \\
\hline Estados Unidos & & & & & 1960 \\
\hline Estonia & 1961 & & & & \\
\hline Francia & 1964,1971 & & 1956 & & \\
\hline Hungría & 1955 & & 1960 & & \\
\hline Italia & 1955 & & & & \\
\hline México & 1957 & & & & 1964 \\
\hline Nicaragua & & 1986 & & & \\
\hline Perú & & 1960 & & & \\
\hline Polonia & 1953 & & 1955 & 1955 & 1955 \\
\hline Rumania & 1955 & & & & \\
\hline Unión Soviética & 1952 & & 1958 & & \\
\hline Uruguay & & & & & 1985,1989 \\
\hline Venezuela & 2008 & & & & \\
\hline TOTAL & 26 & 3 & 9 & 5 & 6 \\
\hline
\end{tabular}

* Cada año corresponde a una edición.

**Se trata de impresiones individuales de los cuentos, excepto la edición polaca de 1955, que incluía en un mismo volumen Marcos Ramírez, Mi madrina y los cuentos Barreteros y El taller.

****La edición de Marcos Ramírez de 1960, está en húngaro; la de 1977, en eslovaco.

Fuente: Anexo 1.

8 Las dos recopilaciones principales son: Fernández, Víctor Hugo. "Notas para una bibliografía circunstancial de Carlos Luis Fallas Sibaja”. Inter-c- $a$ mbio. Revista sobre Centroamérica y el Caribe 9. San José, 2012: 10 (en prensa) y Ramírez Hidalgo, Maricela. Biobibliografía Carlos Luis Fallas Sibaja
1909-1966. San José. Universidad de Costa Rica, 2010: 46-68.

9 Sánchez Mora, Alexánder. "Las múltiples lenguas de Calufa”. Kánina. Revista de Artes y Letras de la Universidad de Costa Rica XXXIV (2). San José, 2010: 45. 
El caso de Marcos Ramírez es de particular interés en relación con esta problemática. El Certificado al Mérito que en 1962, la Fundación William Faulkner le confirió a Fallas por esa novela de sus aventuras infantiles $y$ juveniles, atrajo la atención de algunos editores estadounidenses; sin embargo, por razones desconocidas la traducción no prosperó ${ }^{10}$. La obra indicada, pese a su potencial para captar la atención de audiencias de lectores infantiles y juveniles, solo circuló en Argentina, en contraste con Mamita Yunai, que fue impresa, aparte de en ese país, en Chile, Cuba y México. La diferencia señalada se explica, sin duda, por la promoción de este último libro que hizo el poeta comunista chileno, Pablo Neruda ${ }^{11}$.

Las únicas novelas publicadas en el resto de Centroamérica fueron Gentes y gentecillas (Nicaragua) y Mi madrina (El Salvador), en el contexto de una crisis regional caracterizada por la creciente intervención de Estados Unidos para derrotar al sandinismo y detener las ofensivas revolucionarias salvadoreña y guatemalteca. La ausencia de ediciones en los otros países del istmo probablemente estuvo relacionada con que, en el período 1955-1979, prevalecieron regímenes militares fuertemente identificados con las políticas estadounidenses; sin embargo, llama la atención que en la Guatemala de Juan José Arévalo y Jacobo Arbenz (1945-1954) no fuera impresa alguna de las obras de Fallas, quien alcanzó una significativa proyección pública en

10 Cohn, Deborah. "William Faulkner's IberoAmerican novel project: the politics of translation and the Cold War". Southern Quarterly 42: 2. Winter, 2004: 11.

11 Sánchez Mora, Alexánder. "Las múltiples lenguas de Calufa”. Káñina. Revista de Artes y Letras de la Universidad de Costa Rica XXXIV (2). San José, 2010: 44.
1949, a raíz de la solicitud que hizo el Congreso de esa nación a la Asamblea Constituyente de Costa Rica para que el escritor costarricense fuera liberado (se le condenó a cuatro años de cárcel por el robo de 54 gallinas finas durante la guerra civil de 1948) ${ }^{12}$.

\section{COMERCIALIZACIÓN EN COSTA RICA}

La comparación del cuadro 1 con el cuadro 2 evidencia que en el proceso para difundir $y$ comercializar las novelas y cuentos de Fallas, se pueden diferenciar claramente dos ciclos específicos. El primero, que se extendió entre 1949 y 1964, se caracterizó por el peso que tuvieron las ediciones extranjeras de Mamita Yunai, Gentes y gentecillas y Marcos Ramírez, de las cuales se realizaron 28 en 17 países (11 europeos, 5 latinoamericanos y 1 asiático); en contraste, en ese período, el único libro que fue impreso más de una vez en Costa Rica fue el tercero de los anteriormente citados, que circuló con el sello de Trejos Hermanos en 1963; pero esto ocurrió únicamente después de darse a conocer el Certificado al Mérito otorgado a esa obra por la Fundación William Faulkner.

12 Quirós Vargas, Claudia. Los tribunales de probidad y de sanciones inmediatas. San José. Editorial Costa Rica, 1989: 89-91; United States National Archives. Decimal Files.818.00/4-2849.(April 28, 1949), "Guatemalan Congress sends message to Costa Rican Constituent Assembly urging latter to intervene in favor of Carlos Luis Fallas, exvanguardia deputy and Labor Leader sentenced to prison for activities during Civil War"; y 818.00/71349 (July 13, 1949), "Guatemalan Congress congratulates self on release from Costa Rican imprisonment of Carlos Luis Fallas". El primero de estos documentos consigna que la Confederación de Trabajadores de Guatemala difundió una monografía titulada Quién es Carlos Luis Fallas. 
CUADRO 2

EDICIONES COSTARRICENSES DE LAS PRINCIPALES OBRAS DE FALLAS (1941-2011)

\begin{tabular}{|c|c|c|c|c|c|}
\hline PERÍODO & MAMITA YUNAI & $\begin{array}{c}\text { GENTES Y } \\
\text { GENTECILLAS }\end{array}$ & $\begin{array}{l}\text { MARCOS } \\
\text { RAMÍREZ }\end{array}$ & MI MADRINA & $\begin{array}{c}\text { TRES } \\
\text { CUENTOS* }^{*}\end{array}$ \\
\hline 1941-1949 & 1 & 1 & & & \\
\hline $1950-1959$ & & & 1 & 1 & \\
\hline $1960-1964$ & & & 1 & & \\
\hline $1965-1969$ & 1 & 1 & & 1 & 1 \\
\hline $1970-1974$ & 3 & & 3 & 2 & 1 \\
\hline $1975-1979$ & 3 & 4 & 6 & 4 & 2 \\
\hline $1980-1984$ & 2 & 3 & 2 & 4 & 1 \\
\hline 1985-1989 & 3 & 1 & 3 & 2 & 1 \\
\hline 1990-1994 & & 2 & 2 & 4 & 1 \\
\hline 1995-1999 & 2 & 2 & 3 & 1 & \\
\hline $2000-2004$ & 4 & & 3 & 2 & \\
\hline 2005-2009 & 4 & 1 & 3 & 3 & \\
\hline $2010-2011$ & 1 & & 1 & 2 & \\
\hline TOTAL & 24 & 15 & 28 & 26 & 7 \\
\hline
\end{tabular}

*Las ediciones de 1987 y 1990 fueron publicadas bajo el título de Barreteros y otros cuentos.

Fuente: Anexo 1.

La participación de Fallas en la Junta Directiva de la Editorial Costa Rica, fue motivo de preocupación para el periódico La Nación en febrero de 1960, por la infiltración comunista que podía implicar en esa institución estatal $^{13}$, lo cual no le facilitó la republicación de sus libros. El cuadro 2 patentiza que el segundo ciclo de difusión y comercialización de sus cuentos y novelas inició luego de que se le confirió el Premio Nacional de Literatura y tras su fallecimiento, en mayo de 1966. Entre este año y el 2011, circularon apenas catorce ediciones extranjeras de Mamita Yunai, Gentes y gentecillas, Marcos Ramírez y Mi madrina, además, 88 impresiones costarricenses de esas novelas, más siete de Tres cuentos.

La comercialización de la narrativa de Fallas se intensificó a partir de la década de 1970; de acuerdo con el cuadro 3, las principales entidades involucradas en esta actividad fueron la empresa Lehmann, que controló la publicación de Mamita Yunai y Marcos Ramírez

13 Cuevas Molina, Rafael. El punto sobre la $i$. Políticas culturales en Costa Rica (1948-1990). San José. Ministerio de Cultura, Juventud y Deportes, 1995: 97. entre 1971-1983 y la Editorial Costa Rica, aunque esta última, en un inicio, disponía solo de Mi madrina y Tres cuentos, en 1975 obtuvo los derechos para imprimir Gentes y gentecillas, y en la década de 1980, incorporó por fin a su catálogo las dos primeras obras citadas que, además, eran las más rentables. El predominio logrado, que culminó en el 2009 con una edición en dos volúmenes de esas novelas y cuentos, también empezó a ser desafiado, a partir de ese año, por un impresor privado y otro público: Legado y la Universidad Estatal a Distancia (véase Anexo 1) $)^{14}$. 
CUADRO 3

NÚMERO DE EDICIONES COSTARRICENSES DE LAS OBRAS NARRATIVAS DE FALLAS POR EDITORIAL $(1941-2011)^{*}$

\begin{tabular}{lcccccc}
\hline EDITORIAL & MAMITA & GENTES $Y$ & MARCOS & MI & TRES & TOTAL \\
& YUNAI & GENTECILLAS & RAMÍREZ & MADRINA & CUENTOS & \\
\hline Desconocido & & 1 & & & & 1 \\
Editorial Costa Rica & 14 & 12 & & 15 & 24 & 65 \\
Editorial Universidad Estatal a Distancia & & & & 1 & & 1 \\
Editorial y Distribuidora Centroamericana & 1 & & & & & 1 \\
Falcó & & & 1 & 1 & & 2 \\
Legado & 7 & 1 & & & & 1 \\
Lehmann & 1 & & 11 & & & 1 \\
Principios & 1 & & & & & 1 \\
Soley y Valverde & & 1 & & 1 & & 2 \\
Trejos & 24 & 15 & 12 & 18 & 24 & 93 \\
\hline TOTAL & & & & & & \\
\hline
\end{tabular}

*No incluye las ediciones de la narrativa completa, en dos volúmenes, realizadas por la UACA en 1984 y la Editorial Costa Rica en el 2009.

Fuente: Anexo 1.

El éxito comercial de las obras de Fallas y en particular, de Mamita Yunai y de Marcos Ramírez, se explica en una medida considerable, por su inclusión en las listas de textos obligatorios de secundaria ${ }^{15}$, en una época en que la cobertura en este nivel de enseñanza, calculada con base en los jóvenes de 13 a 17 años que asistían a las aulas, ascendió de 19\% a $52,7 \%$ entre 1960 y $1975^{16}$. La temprana muerte del escritor en 1966 (tenía apenas 57 años), más que los premios que se le otorgaron, fue el factor decisivo que facilitó su rápida inserción en la cultura oficial costarricense; una vez fallecido, su potencial contestatario podía empezar a ser atenuado, como lo hizo la empresa Lehmann en 1971, al desvincular la Costa Rica que él denunciaba de la del presente ${ }^{17}$.

15 El proceso que condujo a esa inclusión debería ser objeto de investigaciones posteriores para determinar quiénes la promovieron y con base en qué criterios.

Molina Jiménez, Iván. "Educación y sociedad en Costa Rica: de 1821 al presente (una historia no autorizada)". Diálogos. Revista Electrónica de Historia 8 (2). Agosto 2007-febrero 2008: 260. En: <http://historia.fcs.ucr.ac.cr/articulos/2007/ vol2/7vol8n2imolina.pdf>

17 Ovares Ramírez, Flora et ál. La casa paterna. Escritura y nación en Costa Rica. San José.

\section{ESTUDIOS ACADÉMICOS}

La construcción cultural de Fallas como un escritor fue de particular interés para el PCCR en la década de 1940, en especial, después de que Mamita Yunai no fuera considerada para participar en un concurso para escoger la mejor novela latinoamericana, convocado por la editorial estadounidense Farrar\&Reinhart; entre los miembros del jurado que debían seleccionar los textos que competirían por Costa Rica, destacaban dos reconocidas figuras de la época: Joaquín García Monge, editor del Repertorio Americano y el poeta y educador Roberto Brenes Mesén. La descalificación indicada preocupó a los dirigentes comunistas porque podía afectar la carrera política del joven escritor (por entonces, regidor en la principal municipalidad del país, la de San José), se desconocía su crecimiento intelectual y desvalorizaba la literatura — de carácter testimonialsocialmente comprometida ${ }^{18}$.

Editorial de la Universidad de Costa Rica, 1993: 227-228.

18 Molina Jiménez, Iván. "Construir un escritor". "Áncora”, La Nación. 18 de enero de 2009: 3-4. 
El reconocimiento dado a la obra de Fallas; sin embargo, no se demoró demasiado, en 1942, Rogelio Sotela lo incluyó en su libro: Escritores de Costa Rica, en la categoría de "Los jóvenes"19"; en 1944, el profesor Martin E. Erickson, de Northwestern University, publicó un artículo en la prestigiosa revista Hispania acerca de la literatura centroamericana, en el que destacó la ventaja costarricense en el campo de la novela y destacó, entre otros, el aporte de Mamita Yunai ${ }^{20}$ y en 1947, alguien publicó, con las siglas "A. F. C." una elogiosa reseña de Gentes y gentecillas en la Revista de la Universidad de Costa Rica ${ }^{21}$. La importancia de este comentario, por la validación académica que implicaba, fue debidamente considerada en el periódico comunista Trabajo, que señaló en su edición del 20 de diciembre del último año indicado:

... muchos comentarios de justo elogio hemos leído ya sobre la última novela del celebrado autor de MAMITA YUNAI. Unos de ellos escritos en Costa Rica y otros, los más y de mayor aliento, venidos de otros países en donde la obra última de Carlos Luis Fallas ha sido medida en dimensiones de amplitud y holgura con la imparcialidad de quien juzga los hechos y las obras independientemente de los nexos posibles de simpatía o animadversión entre el que esos juicios escribe $y$ el autor de las obras $y$ los hechos. Muchos comentarios hemos leído... pero pocos entre ellos que tengan la significación que tiene... el ponderado juicio literario aparecido en las páginas... académicas de la revista universitaria... No podemos decir que este

19 Sotela, Rogelio (ed.). Escritores de Costa Rica. San José. Lehmann, 1942: 885.

20 Erickson, Martin E. "Central America: the literary scene, 1943”. Hispania 27 (2). May, 1944: 153. Los comunistas probablemente no conocieron este artículo, que también destacaba las obras de José Marín Cañas, Fabián Dobles y Adolfo Herrera García.

21 A. F. C. "Gentes y gentecillas por Carlos Luis Fallas". Revista de la Universidad de Costa Rica 2. San José, 1947: 175-177. juicio elogioso por muchos conceptos para nuestro camarada Fallas venga desde las propias filas de nuestro Partido o desde las filas de los amigos... De sobra conocemos a nuestros militantes $y$ amigos y sabemos bien que ellos no tienen acceso a las páginas de la revista del Alma Máter. Ese juicio proviene, y por ello es que tiene alta significación para nosotros, de otro campamento. Y en ello estriba justamente su mérito principal, en que es el reflejo de una apreciación a cubierto de toda sospecha de parciali$\mathrm{dad}^{22}$.

La atención prestada por los académicos a la obra de Fallas; sin embargo, únicamente se intensificó a partir de la década de 1970 (véase el cuadro 4), con una proporción significativa de trabajos de graduación (50\%) y estudios $(26,7 \%)$ defendidos o publicados en el exterior. El alza indicada tuvo por contexto la apertura política y cultural que Costa Rica experimentó en esa época; después de la protesta estudiantil efectuada el 24 de abril de 1970, contra el contrato firmado por el gobierno y la transnacional ALCOA, las organizaciones socialistas $y$ comunistas crecieron $y$ se diversificaron; se derogó la disposición que ilegalizó al PCCR tras la guerra civil de 1948; el Partido Liberación Nacional profundizó sus políticas sociales y fueron establecidas tres nuevas universidades públicas: el Instituto Tecnológico (1971), la Universidad Nacional (1973) y la Universidad Estatal a Distancia $(1977)^{23}$.

22 "Carlos Luis Fallas en el banquillo de la crítica". Trabajo. 20 de diciembre de 1947: 1 y 4 .

23 Pacheco Fernández, Francisco Antonio. "La educación superior”. Rodríguez Vega, Eugenio (ed.). Costa Rica en el siglo XX, t. I. San José. Editorial Universidad Estatal a Distancia, 2004: 108-158; Cuevas Molina, Rafael. El punto sobre la i. pp. 131139; Mesa-Lago, Carmelo. Buscando un modelo económico en América Latina. ¿Mercado, socialista o mixto? Chile, Cuba y Costa Rica. Caracas. Nueva Sociedad, 2002: 424-453; Salom, Roberto. La crisis de la izquierda en Costa Rica. San José: Editorial Porvenir, 1987. 
CUADRO 4

TESIS Y ESTUDIOS ACADÉMICOS SOBRE LAS OBRAS DE FALLAS (1941-2011)*

\begin{tabular}{|c|c|c|c|c|c|}
\hline PERÍODO & $\begin{array}{c}\text { TESIS } \\
\text { DEFENDIDAS EN } \\
\text { COSTA RICA }\end{array}$ & $\begin{array}{c}\text { TESIS } \\
\text { DEFENDIDAS EN } \\
\text { EL EXTERIOR }\end{array}$ & $\begin{array}{c}\text { ESTUDIOS } \\
\text { PUBLICADOS EN } \\
\text { COSTA RICA }\end{array}$ & $\begin{array}{c}\text { ESTUDIOS } \\
\text { PUBLICADOS } \\
\text { EN EL EXTERIOR }\end{array}$ & TOTAL \\
\hline 1941-1949 & & & 1 & & 1 \\
\hline $1950-1959$ & & 1 & & & 1 \\
\hline $1960-1964$ & 1 & & & & 1 \\
\hline 1965-1969 & & & & & \\
\hline $1970-1974$ & & 2 & 1 & 1 & 4 \\
\hline $1975-1979$ & 5 & 1 & 2 & 4 & 12 \\
\hline 1980-1984 & & 1 & 7 & 2 & 10 \\
\hline 1985-1989 & 2 & & 5 & 2 & 9 \\
\hline 1990-1994 & 2 & 1 & 1 & 1 & 5 \\
\hline 1995-1999 & 1 & 1 & 2 & 1 & 5 \\
\hline $2000-2004$ & & 2 & 1 & & 3 \\
\hline 2005-2009 & & 2 & 17 & 3 & 22 \\
\hline $2010-2011$ & & & 7 & 2 & 9 \\
\hline TOTAL & 11 & 11 & 44 & 16 & 82 \\
\hline
\end{tabular}

*No incluye tesis ni estudios sobre la vida de Fallas.

Fuente: Anexo 2.

El incremento en la población universitaria, que ascendió de 5,7 a 15,9 de los jóvenes de 18 a 24 años entre 1970 y $1980^{24}$, fue la base para una mayor producción académica en todos los campos, incluida la literatura. El proceso indicado coincidió con la publicación de las dos principales biografías de Fallas, escritas por Víctor Manuel Arroyo (1973) y Marielos Aguilar Hernández (1983), con el benemeritazgo que le otorgó la Asamblea Legislativa en 1977, con el cincuentenario de la huelga bananera de agosto-septiembre de 1934 y con la crisis político-militar de Centroamérica que atrajo a numerosos investigadores extranjeros (especialmente de Europa y Estados Unidos) y agudizó el conflicto entre los partidarios de los sandinistas y de los movimientos revolucionarios en El Salvador y Guatemala; sus adversarios, por lo general, fuertemente identificados con la política estadounidense.

El final de la crisis centroamericana $y$ la transformación posterior de las sociedades $y$

24 Molina Jiménez, Iván. "Educación y sociedad en Costa Rica: de 1821 al presente (una historia no autorizada)". Diálogos. Revista Electrónica de Historia 8 (2). Agosto 2007-febrero 2008: 260. En: <http://historia.fcs.ucr.ac.cr/articulos/2007/ vol2/7vol8n2imolina.pdf> economías del istmo, a tono con las exigencias del libre mercado y de la globalización ${ }^{25}$, fueron el marco de un decreciente interés por las obras de Fallas, en cuyo curso Marcos Ramírez primero y Mamita Yunai después, fueron excluidas de la lista de textos obligatorios de secundaria ${ }^{26}$. La tendencia señalada, sin embargo, se modificó entre finales de la década del 2000 e inicios de la del 2010, un cambio vinculado con la conmemoración de los cien años del nacimiento del escritor; al tiempo que los investigadores

$25 \quad$ Pérez Brignoli, Héctor. "Las ambigüedades del crecimiento: dos siglos de historia económica de Centroamérica, 1810-2010". Luis Bértola, Luis y Gerchunoff, Pablo (comps.). Institucionalidad y desarrollo económico en América Latina. Santiago. CEPAL, 2011: 115-120.

26 Ordóñez, Jaime. "En busca de Marcos Ramírez". "Página Abierta", Diario Extra. 27 de octubre de 2009. En: <http://paginaabierta.cr/index.php/ component/content/article/41-la-columna-dejaime-ordonez/135-en-busca-de-marcos-ramirez.html>. Segura Cano, Diego; Cajina Vázquez, Olga y Villalobos Trigueros, Irina. "Reviviendo a Martí en las aulas costarricenses". InterSedes. Revista Electrónica de las Sedes Regionales de la Universidad de Costa Rica XI (21). San José, 2010: 111. En: <http://www.latindex.ucr.ac.cr/intersedes-21/intersedes-21-10.pdf> 
sociales $y$ literarios empezaban a considerar sus novelas y cuentos desde perspectivas étnicas, ecológicas, lingüísticas, de género y regionales, varias revistas académicas costarricenses publicaron números o secciones especiales con motivo del centenario.

El cambio señalado coincidió con una nueva oleada de movimientos nacionalistas $y$ antiimperialistas relacionados con el creciente desencanto con los partidos políticos, con las crecientes denuncias de corrupción que involucraban a funcionarios públicos y empresarios, en particular, con la lucha contra la privatización de instituciones públicas y el Tratado de Libre Comercio entre Centroamérica, República Dominicana y Estados Unidos ${ }^{27}$. La revalorización de Fallas y su producción literaria, en este contexto, explica que al final, fracasara el intento del Ministerio de Educación Pública por excluir Mamita Yunai como lectura obligatoria en los colegios, dado el fuerte rechazo que esta disposición provocó y que fue articulado mediante las redes sociales ${ }^{28}$.

\section{EPÍLOGO}

La narrativa de Fallas fue elaborada en un período bastante corto, que se extendió entre 1940 y $1951^{29}$; ¿por qué no escribió más novelas o cuentos? El propio escritor, en el prólogo a la edición cubana de 1960, ofreció una respuesta:

27 Alvarenga Venutolo, Patricia. De vecinos a ciudadanos. Movimientos comunales y luchas cívicas en la historia contemporánea de Costa Rica. Heredia. Editorial Universidad Nacional, 2005: 263-298. Rayner, Jeremy. "Vecinos, ciudadanos y patriotas: los Comités Patrióticos y el espacio-temporalidad de oposición al neoliberalismo en Costa Rica”. Revista de Ciencias Sociales 121. San José, 2008: 71-87.

28 Segura Cano, Diego; Cajina Vázquez, Olga y Villalobos Trigueros, Irina. "Reviviendo a Martí en las aulas costarricenses". InterSedes. Revista Electrónica de las Sedes Regionales de la Universidad de Costa Rica XI (21). San José, 2010: 111. En: <http://www.latindex.ucr.ac.cr/intersedes-21/intersedes-21-10.pdf>

29 Picado Gómez, Manuel. "Carlos Luis Fallas: visión de conjunto". Revista Iberoamericana LIII (138139). Enero-junio 1987: 227.
... en Mamita Yunai dejamos de lado, calculadamente, todo el brutal trabajo de la formación de fincas, así como el de las bananeras ya en plena producción, porque pensaba utilizarlos en un segundo tomo cuyo argumento central debía ser la gran huelga bananera de 1934. ¡Formidable argumento para una segunda novela antiimperialista! ...Se me quedó ese segundo tomo en el tintero, como en el tintero se me han ido quedando también el segundo tomo de MARCOS RAMIREZ y la continuación de EL TALLER, incluído como novela corta en mi libro MI MADRINA, $y$ que apenas es la parte primera de una proyectada amplia novela sindical... ¿Exceso de trabajo partidista, de diario trabajo revolucionario? No. Vergonzosa desidia mía, injustificable incumplimiento de una muy importante tarea revolucionaria. ¡Al fin tengo el valor de hacerme esta franca y pública autocrítica $^{30 \text { ! }}$

La explicación anterior, sin embargo, puede ser impugnada fácilmente en ese mismo año de 1960, porque aparte del prólogo para la edición cubana, Fallas escribió un extenso $y$ detallado informe sobre el conflicto agrario en Guanacaste ${ }^{31} y$ apenas regresó de La Habana, elaboró un amplio ensayo acerca de la Cuba revolucionaria, el cual fue publicado entre noviembre y diciembre en el periódico Adelante $^{32}$. Los Anexos 1 y 2, a su vez, sugieren una respuesta adicional a la pregunta planteada: en los tres lustros anteriores a su fallecimiento, el escritor comunista debió dedicar una parte importante de su tiempo a la administración de su propia obra, lo que implicó viajes al exterior, colaborar con los traductores $y$ preparar textos adicionales para las ediciones extranjeras.

$30 \quad$ Fallas Sibaja, Carlos Luis. "Prólogo del autor para esta edición cubana". Mamita Yunai. La Habana. Editorial Vanguardia Obrera, 1960: 10-11.

31 Fallas Sibaja, Carlos Luis. Don Bárbaro. San José: Comité de Solidaridad Nacional, 1960.

32 Aguilar Hernández, M. Carlos Luis Fallas. pp.243244. 
Las tareas indicadas, Fallas las combinó con labores políticas y sindicales, la defensa de sus derechos constitucionales (su correspondencia fue violada en 1954 y en 1962 fue apresado por portar propaganda comunista), la lucha por lograr la participación electoral del PCCR y la preparación de ensayos, informes, conferencias y artículos periodísticos ${ }^{33}$.

33 Aguilar Hernández, M. Carlos Luis Fallas. pp. 238260.
La "desidia" de la que se culpó en La Habana tampoco le impidió empezar a redactar dos libros más que no fueron terminados, "Rojo y verde", una crónica de su etapa inicial como líder de los trabajadores y "Desde el Nuevo Mundo", cartas a propósito de su estancia en la Unión Soviética, en 1954; además, completó un relato de viajes, Un mes en la China roja, el cual publicó por entregas en Adelante, en 1957 y fue reimpreso, veinte años después, por la Editorial de la Universidad de Costa Rica. 
ANEXO 1

\section{BIBLIOGRAFÍA DE CARLOS LUIS FALLAS}

\section{NARRATIVA}

Mamita Yunai. San José: Editorial Soley y Valverde, 194134; San José: Editorial Principios, 1966; San José: Editorial y Distribuidora Centroamericana, 1970; San José: Lehmann, $1971^{35}$; San José: Lehmann, 1974; San José: Lehmann, 1975; San José: Lehmann, 1977; San José: Lehmann, 1978; San José: Lehmann, 1980; San José: Lehmann, 1983; San José: Editorial Costa Rica, 1986; San José: Editorial Costa Rica, 1989; San José: Editorial Costa Rica, 1989; San José: Editorial Costa Rica, 1995; San José: Editorial Costa Rica, 1998; San José: Editorial Costa Rica, 2000; San José: Editorial Costa Rica, 2002; San José: Editorial Costa Rica, 2003; San José: Editorial Costa Rica, 2004; San José: Editorial Costa Rica, 2005; San José: Editorial Costa Rica, 2006; San José: Editorial Costa Rica, 2007; San José: Editorial Costa Rica, 2008; San José: Editorial Costa Rica, 2010 .

Ediciones en español no costarricenses: Santiago: Nascimento, 1949; Buenos

$34 \quad$ Algunas ediciones tienen como subtítulo: "una novela" o "el infierno de las bananeras". La primera edición contenía una dedicatoria ("Dedico este libro a mis excompañeros de trabajo: los 'linieros' de la Zona Atlántica") y un colofón ("Este libro fue escrito por un obrero para participar en el concurso de la mejor novela latinoamericana de 1940 . El jurado costarricense "por considerar que no se podía tomar en cuenta como novela, lo desechó”") que desaparecieron en la mayoría de las impresiones posteriores.

$35 \quad$ Incluye una nota editorial que desvincula la Costa Rica de la novela, de la de 1971, la cual fue reproducida en las ediciones posteriores de la Lehmann $y$ en la de Castellote.
Aires: Editorial Platina, 1955; Buenos Aires: Editorial Platina, 1956; México: Fondo de Cultura Popular, 1957; La Habana: Editorial "Vanguardia Obrera", 1960; La Habana: Imprenta Nacional de Cuba, 1961 ${ }^{36}$; La Habana: Organización Continental de los Festivales del Libro, 196137; Santiago: Quimantú, 1972; La Habana: Arte y Literatura, 1975; Madrid: Castellote, 1976; Caracas: Fondo Editorial el Perro y la Rana, $2008^{38}$.

Traducciones: МамитаЮнай. Москва: Изд-воиностранной литературы, 1952; MaminkaJunaj. Praha: SNKLHU, Brnenskéknihtisk, 1953; Mateczka Yunai. Warszawa: Czytelnik, 1953; Die grüneHölle. Berlin: Verl. Volk u. Welt, $1954^{39}$; Mamička Junaj. [Bratislava]: Slovenskýspisovatel', 1954; Mamita Yunai. Bucureşti: Editura de StatpentruLiteraturăşiArtă, 1955; Mamita Yunai. Roma: Edizioni di Cultura Sociale, 1955; Mamita Yunai. Budapest: Új M. Kiadó, 1955; Мамита Юнай. Роман. София, Нар. култура, 1957; 绿地狱. 上海: 新文艺出版社, 1958 [Infierno verde. Shanghai: Editorial Nueva Literatura, 1958] ${ }^{40}$; Die grüneHölle. Roman. Berlin: Verl. Volk u. Welt, 1961; Rohelinepõrgu: Mamita Yunai: romaan. Tallinn: EestiRiiklikKirjastus, 1961; Mamita Yunai (Maman Banane and Co.): romancostaricein. Paris: Les

36 En contraste con las otras ediciones cubanas, no incluye la parte cuarta.

37 También puede aparecer como publicada por la Editorial Lex o por la EPCC en los años 1950 y 1960; en otras referencias, aparece 1959 como año de publicación.

38 Se trata de una impresión basada en la edición de 1975 de la Lehmann, que tiene como subtítulo: "el infierno de las bananeras"; no incluye el prólogo de Víctor Manuel Arroyo ni la autobiografía de Fallas.

39 Incluye una traducción al alemán del poema de Pablo Neruda dedicado al personaje Calero, que figura también en la edición de 1961.

40 La traducción se hizo con base en la edición alemana de 1954; algunas bibliotecas consignan 1959 como año de publicación. 
Editeurs Français Réunis, 1964; Nëhijen e bananeve. Tiranë, ShtëpiaBotuese "Naim Frashëri", 1971; "Mamita Yunai". L'Amérique latine. Paris: Editions du Burin-ÉditionsMartinsart, 1971:13731341; "In the Shadow of the Banana Tree" [fragmento]. Ras, Barbara. Costa Rica: A Traveler's Literary Companion. San Francisco: Whereabouts Press, 1994 : 121-133.

"La dueña de la guitarra de las conchas de colores". Sotela, Rogelio (ed.). Escritores de Costa Rica. San José: Lehmann, 1942: 777-782.

Ediciones en español no costarricenses: Yates, Donald A. y Dalbor, John B. (eds.). Imaginación y fantasía: cuentos de las Américas. New York, Holt, Rinehart y Winston, 1960: 75-83; Menton, Seymour (ed.). El cuento costarricense. México y Lawrence: Ediciones de Andrea y University of Kansas Press, 1964: 115119; Barraza Arriola, Marco Antonio (ed.). Antología de escritores del istmo centroamericano. Santa Tecla: Clásicos Roxsil, 1999: 377-384.

Gentes y gentecillas. San José: s. e., 1947²; San José: Trejos, 196743; San José: Editorial Costa Rica, 1975; San José: Editorial Costa Rica, 1977; San José: Editorial Costa Rica, 1977; San José: Editorial Costa Rica, 1979; San José: Editorial Costa Rica, 1981; San José: Editorial Costa Rica, 1981; San José: Editorial Costa Rica, 1984; San José: Editorial Costa Rica, 1986; San José: Editorial Costa Rica, 19934; San José: Editorial

$41 \quad$ En ciertas referencias, se consigna que la edición fue realizada en Montreal, en 1972; en contraste con la impresión de 1964, no incluye la parte cuarta.

Algunas ediciones tienen como subtítulo: novela. La versión publicada en 1947, está fechada en agosto de 1942, dato omitido en impresiones posteriores.

43 En algunas referencias, la casa editora aparece como Editorial Costa Rica.
Costa Rica, 1994; San José: Editorial Costa Rica, 1995; San José: Editorial Costa Rica, 1998; San José: Legado, 2009.

Ediciones en español no costarricenses: Lima: Editorial LatinoamericanaOrganización Continental de los Festivales del Libro, $1960^{45}$; Managua: Editorial Nueva Nicaragua, 1986; La Habana: Arte y Literatura, 1987.

Marcos Ramírez. Aventuras de un muchacho; novela. San José: Falcó, 1952; San José: Trejos Hnos., 1963 ${ }^{46}$; San José: Lehmann, 1971; San José: Lehmann, 1973; San José: Lehmann, 1974; San José: Lehmann, 1975; San José: Lehmann, 1975; San José: Lehmann, 1976; San José: Lehmann, 1977; San José: Lehmann, 1978; San José: Lehmann, 1979; San José: Lehmann, 1980; San José: Lehmann, 1982; San José: Editorial Costa Rica, 1985; San José: Editorial Costa Rica, 1986; San José: Editorial Costa Rica, 1989; San José: Editorial Costa Rica, 1990; San José: Editorial Costa Rica, 1993; San José: Editorial Costa Rica, 1995; San José: Editorial Costa Rica, 1997; San José: Editorial Costa Rica, 1998; San José: Editorial Costa Rica, 2000; San José: Editorial Costa Rica, 2002; San José: Editorial Costa Rica, 2003; San José: Editorial Costa Rica, 2006; San José: Editorial Costa Rica, 2007; San José: Editorial Costa Rica, 2008; San José: Editorial Costa Rica, 2010.

Ediciones en español no costarricenses: Buenos Aires: Editorial Platina, 1957.

$45 \quad$ La fecha de publicación a veces aparece como 1959 o no se especifica.

46 Esta edición incluye un facsímil del Certificado al Mérito otorgado por la Fundación Faulkner en 1962, el cual fue reproducido en las impresiones de la Lehmann y desapareció en las de la Editorial Costa Rica. 
Traducciones: Marcos Ramírez. Berlin: NeuesLeben, 195547; Skata $i$ inneopowiadania ${ }^{48}$. Warszawa: Czytelnik, 1955; Marcos Ramirez: aventures d'unenfant. Paris: Gallimard, 1956; Маркос Рамирес: приключения костариканского мальчишки . повесть. Москва, Гос. изд-во детско йлит-ры, 1958; Egy kölyök kalandjai. Budapest: Móra Ferenc Könyvkiadó, 1960; Egy kölyök kalandjai. Bratislava: Szépirod. Kiadó, 1960; Маркос Рамирес: Приключения та на едно момче: Роман. София. НСОФ, 1968; Dobrodružstvo môjho života. Bratislava: Mladéletá, 1977.

Mi madrina. San José: Falcó, 19549' San José: Editorial Costa Rica, 196750; San José: Editorial Costa Rica, 1972; San José: Editorial Costa Rica, 1973; San José: Editorial Costa Rica, 1975; San José: Editorial Costa Rica, 1977; San José: Editorial Costa Rica, 1978; San José: Editorial Costa Rica, 1978; San José: Editorial Costa Rica, 1981; San José: Editorial Costa Rica, 1982; San José: Editorial Costa Rica, 1983; San José: Editorial Costa Rica, 1984; San José: Editorial Costa Rica, 1986; San José: Editorial Costa Rica, 1988; San José: Editorial Costa Rica, 1990; San José: Editorial Costa Rica, 1991; San José: Editorial Costa Rica, 1993; San José: Editorial Costa Rica, 1994; San José: Editorial Costa Rica, 1995; San José: Editorial Costa Rica, 2000; San José: Editorial Costa Rica, 2001; San José:

$47 \quad$ La dedicatoria incluida en esta versión ("A la memoria de mi madre, ADELINA FALLAS") se consigna también en la edición argentina de 1957, pero fue omitida en la mayoría de las impresiones costarricenses.

El volumen comprende las novelas Marcos Ramírez, Mi madrina y los cuentos "Barreteros" y "El taller".

49 Incluye los cuentos "Barreteros" y "El taller".

50 A partir de esta edición, incluye únicamente el texto de Mi madrina.
Editorial Costa Rica, 2005; San José: Editorial Costa Rica, 2007; San José: Editorial Costa Rica, 2008; San José: Editorial Costa Rica, 2011; San José: Editorial Universidad Estatal a Distancia, 2011.

Ediciones en español no costarricenses: San Salvador. Canoa Editores, 1986: 10-102; San Salvador. Canoa Editores, 1989: 10-102; San Salvador. Canoa Editores, 1993: 10-102; San Salvador. Canoa Editores, 1995:10-102 ${ }^{51}$.

Traducciones: Skata $i$ inne opowiadania ${ }^{52}$.Warszawa, Czytelnik, 1955.

Tres cuentos $^{53}$. San José: Editorial Costa Rica, 1967; San José: Editorial Costa Rica, 1973; San José: Editorial Costa Rica, 1975; San José: Editorial Costa Rica, 1978; San José: Editorial Costa Rica, 1980; San José: Editorial Costa Rica, 1983.

Narrativa de Carlos Luis Fallas. 2 volúmenes. San José: Studium Generale Costarricense, 1984.

"Barreteros". Ramírez, Sergio (ed.). Antología del cuento centroamericano. T. I. San José. Editorial Universitaria Centroamericana, 1973: 541-587; Chase, Alfonso (comp.). Narrativa contemporánea de Costa Rica. T. I. San José. Ministerio de Cultura, Juventud y Deportes, 1975: 277-321; González Picado, Jézer (comp.). Antología del relato costarricense, 1930-1970. San José. Editorial de la Universidad de Costa Rica, 2000: 48-84.

$51 \quad$ Este volumen incluye también Los juegos furtivos de Alfonso Chase.

52 El volumen comprende las novelas Marcos Ramírez, Mi madrina y los cuentos "Barreteros" y "El taller".

53 Incluye los cuentos "La dueña de la guitarra de las conchas de colores", "Barreteros" y "El taller". 
Ediciones en español no costarricenses: Raviolo, Heber (ed.). Panorama del cuento costarricense. Montevideo. Ediciones de la Banda Oriental, 1985:17-45. Versión en polaco: Skata $i$ inne opowiadania. Warszawa, Czytelnik, $1955^{54}$.

Narrativa de Carlos Luis Fallas. 2 volúmenes. San José: Studium Generale Costarricense, 1984.

Barreteros $y$ otros cuentos ${ }^{55}$. San José: Editorial Costa Rica, 1987; San José: Editorial Costa Rica, 1990.

"El taller". Y nos dio el cuero! Montevideo. Uruguay, 198956: 9-80. Versión en polaco: Skata $i$ inne opowiadania. Warszawa, Czytelnik, $1955^{57}$.

Obra narrativa. 2 volúmenes. San José: Editorial Costa Rica, 2009.

\section{ESCRITOS POLÍTICOS, SOCIALES, HISTÓRICOS Y PERSONALES}

El peligro de la dictadura. Las elecciones y la organización sindical. San José: Falcó Hermanos, 1935; reimpreso en: Lyra, Carmen y Fallas, Carlos Luis. Ensayos politicos. San José. Editorial de la Universidad de Costa Rica, 2000: 99-142. De mi vida. T. II. Heredia. Editorial Universidad Nacional, 2012: 138-161.

[Cartas a Otilio Ulate]. Guatemala: ¿Confederación de Trabajadores de Guatemala? $1949^{58}$.

$54 \quad$ El volumen comprende las novelas Marcos Ramírez, Mi madrina y los cuentos "Barreteros" y "El taller".

55

Previamente publicado como Tres cuentos.

56 Incluye también "Miguel Mármol" de Roque Dalton.

$57 \quad$ El volumen comprende las novelas Marcos Ramírez, Mi madrina y los cuentos "Barreteros" y "El taller".

58 La información procede de: Fallas Sibaja, C. De mi vida. T. II. Heredia. Editorial Universidad Nacional, 2012: 215-218.
El canal de Nicaragua y nuestra soberanía: conferencia dictada por Carlos Luis Fallas, la noche del jueves 20 de abril de 1950, en San José, C.R. San José: Unión de Mujeres Carmen Lyra, 1950; reimpreso en: De mi vida. T. II. Heredia. Editorial Universidad Nacional, 2012: 162-170.

"Las congojas de Marcos Ramírez en Polonia (dos cartas)”. Marcos Ramírez. San José: Falcó, 1952: $203-207^{59}$.

Reseña de la penetración e intervención yanqui en Centroamérica. México: Fondo de Cultura Popular, 1954; reimpreso en: Revista Abra 5-6. Heredia, agosto 1987: 341-353; De mi vida. T. II. Heredia. Editorial Universidad Nacional, 2012: 182-193.

Calderón Guardia, José Figueres y Otilio Ulate: a la luz de los últimos acontecimientos políticos. San José: s. e., 1955 (en colaboración con Eduardo Mora).

Luchemos por este plan contra la crisis. San José: s. e., 1955 (en colaboración con Manuel Mora, Eduardo Mora, Arnoldo Ferreto y Rodolfo Guzmán).

La gran huelga bananera del Atlántico de 1934. San José: CGTC, 1955; reimpreso en: Mamita Yunai. México. Fondo de Cultura Popular, 1957: 207-22860. Mamita Yunai. La Habana. Editorial "Vanguardia Obrera", 1960: 309. 341; La Habana. Organización Continental de los Festivales del Libro, 1961: 227-254; La Habana. Editorial de Arte y Literatura, 1975: 239-266; Madrid, Castellote, 1976: 193-214; Caracas. Fondo Editorial el Perro y la Rana, 2008: 207-229 y en las ediciones costarricenses de esa novela a partir de 1966. Versión en francés: Mamita Yunai (Maman Banane and Co.): roman costaricein. Paris. Les Editeurs Français Réunis, 1964: 261-287; en inglés: "The Great Atlantic Banana Plantation Strike of 1934"

$59 \quad$ Incluye una carta de la traductora al polaco de Marcos Ramírez, Elena Bychowska y la respuesta de Fallas.

60 Las versiones de 1955 y 1957 incluyen divisiones, que desaparecieron en la edición cubana de 1960. 
[fragmento]. Edelman, Marc y Kenen, Joanne (eds.). The Costa Rica Reader. New York. Grove Weidenfeld, 1989: 76-82.

"Autobiografía”. Mamita Yunai. México: Fondo de Cultura Popular, 1957, páginas sin numerar; reimpresa en: Mamita Yunai. La Habana. Editorial "Vanguardia Obrera", 1960: 13-16; Madrid. Castellote, 1976: 11-13 y en las ediciones costarricenses de esa novela a partir de 1966. Versión en francés: "Autobiographie". Mamita Yunai (Maman Banane and Co.): roman costaricein. Paris. Les Editeurs Français Réunis, 1964: 12-14; en búlgaro: “Автобиографични бележки”. Маркос Рамирес: Приключенията на едно момче: Роман. София. НС ОФ, 1968: 7-8; en inglés: "Carlos Luis Fallas". Flores, Angel (ed.). Spanish American Authors. The Twentieth Century. New York. Wilson, 1992: 304-305.

“Авторьт за себе си”. Мамита Юнай: Роман. София, Нар. култура, 1957: 3-8; De mi vida. T. II. Heredia. Editorial Universidad Nacional, 2012: $23-27^{61}$.

"Prólogo del autor para esta edición cubana". Mamita Yunai. La Habana: Editorial "Vanguardia Obrera", 1960:17-20; reimpreso como "Prólogo del autor para edición cubana". Mamita Yunai. San José. Editorial Principios, 1966:17-20. De mi vida. T. II. Heredia. Editorial Universidad Nacional, 2012: 65-66. Versión en francés: "Préface de l'auteur a l'édition cubaine". Mamita Yunai (Maman Banane and Co.): roman costaricein. Paris. Les Editeurs Français Réunis, 1964: 9-11.

Plena solidaridad con la nación panameña: declaramos nuestro apoyo incondicional a la lucha reivindicadora del pueblo panameño $y$ condenamos el alevoso crimen del imperialismo yanqui. San José: s. e., 1964 (en colaboración con Eduardo Mora y Arnoldo Ferreto).

61 Se trata, con algunas pequeñas diferencias, de la biografía que, desde Moscú, Fallas le envió a Claude Morgan el 26 de abril de 1954. La versión búlgara está fechada en San José el 2 de noviembre de 1956 .
Don Bárbaro. San José: Comité de Solidaridad Nacional, 1960; reimpreso en: Cuadernos Prometeo 6. Heredia, 1978: 7-19; De mi vida. T. II. Heredia. Editorial Universidad Nacional, 2012: 109-131.

Un mes en la China roja. San José: Editorial de la Universidad de Costa Rica, 1977; reimpreso en: De mi vida. T. I. Heredia. Editorial Universidad Nacional, 2012: 135-224.

"Carta a Luis Carlos Fallas". Revista Comunicación 18. Edición especial. Cartago, 2009: 82.

Cuenta Braña: un mecánico comunista en la Europa nazi. Heredia: Editorial Universidad Nacional, 2010; reimpreso en: De mi vida. T. II. Heredia. Editorial Universidad Nacional, 2012: 89-108.

De mi vida. 2 volúmenes. Heredia. Editorial Universidad Nacional, 2012.

\section{TEXTOS DE CIRCULACIÓN LIMITADA O NO PUBLICADOS ESCRITOS CON OTROS AUTORES}

"Al colocarse bajo la tutela de Ulate, la dirección calderonista ha tirado por la borda la política de justicia social". 1957 (en colaboración con Manuel Mora, Eduardo Mora y Arnoldo Ferreto).

"Fuerzas extrañas conjuran contra nuestro sistema político democrático. Un análisis de la situación política nacional”. 1960 (en colaboración con Manuel Mora, Arnoldo Ferreto, Jaime Cerdas y Eduardo Mora).

"AAbajo el militarismo! Dos discursos contra el Gobierno”. 1963 (en colaboración con Adolfo Herrera García).

"Llamamos a impedir que se lance a Costa Rica al abismo de la dictadura y el militarismo". 1963 (en colaboración con Arnoldo Ferreto y Eduardo Mora).

"Llamamiento para compactar las fuerzas de izquierda”. 1964 (en colaboración con 
Manuel Mora, Arnoldo Ferreto, Eduardo Mora, Humberto Vargas y Mario Solís).

\section{VERSIONES PUBLICADAS EN PERIÓDICOS Y REVISTAS}

"La farsa de las últimas elecciones en Talamanca". Trabajo. Del 16 de marzo al 7 de septiembre, 1940 (versión previa a lo que fuera la primera parte de Mamita Yunai).

"Cuenta Braña". Trabajo. Del 2 de marzo al 4 de mayo, 1946.

"El taller". Adelante. Del 17 de enero al 20 de junio, 1954 (esta versión está dividida en cuatro capítulos).
"Apuntes sobre el problema de la burguesía nacional en la Nueva China". Adelante. Del 25 de noviembre, 1956 al 24 de noviembre, 1957 (versión previa de Un mes en la China roja) ${ }^{62}$.

"Marcos Ramírez. Aventuras de un muchacho". Brecha 3:3. San José. Noviembre, 1958: 12-13, 16 (fragmento del capítulo II).

"Informe sobre el problema agrario de La Cruz". La República. Junio-julio, 1960 (primera versión de Don Bárbaro).

62 Las primeras entregas tienen títulos distintos; a partir de la edición del 10 de febrero de 1957, el material se uniformó como Apuntes sobre mi viaje a la Nueva China.

Fuente: WorldCat, GoogleBooks, Sala de Libros Antiguos y Especiales de la Biblioteca Joaquín García Monge de la Universidad Nacional, bibliotecas nacionales y universitarias de los países en que fueron publicados los libros de Fallas, Trabajo (1940 y 1946), Adelante (1954 y 1956-1957), Brecha (1958) y La República (1960). 
ANEXO 2

\section{BIBLIOGRAFÍA SOBRE CARLOS LUIS FALLAS Y SU OBRA}

\section{BIOGRAFÍAS Y SEMBLANZAS}

Acuña Ortega, Víctor Hugo. "Carlos Luis Fallas: una biografía política”. Aportes 4 (18). San José, 1984: 36-37.

Aguilar Hernández, Marielos. "Carlos Luis Fallas: semblanza de un escritor". Pensamiento Revolucionario 4. San José, 1984: 44-49.

Aguilar Hernández, Marielos. Carlos Luis Fallas: su época y sus luchas. San José: Editorial Porvenir, 1983.

Aguilar Hernández, Marielos. "Carlos Luis Fallas y el partido comunista de Costa Rica". [Tesis de Licenciatura en Historia]. Universidad de Costa Rica, 1981.

Aragón, Maureen. "Carlos Luis Fallas: un pintor de la realidad costarricense". Magisterio 9. San José, 2000: 25-26.

Arroyo, Víctor Manuel. Carlos Luis Fallas. San José: Ministerio de Cultura, Juventud y Deportes, 1973.

Chacón Araya, Germán. "Carlos Luis Fallas: militante comunista”. Revista Comunicación 18. Nro. especial. Cartago, 2009: 47-50.

Contreras Álvarez, Gerardo y Villalobos, Ana Irene. "Carlos Luis Fallas Sibaja". Revista Comunicación 11 (3). Cartago, 2001: 132-136; reimpreso con un epígrafe y sin bibliografía en: Contreras Álvarez, Gerardo. Vivencias del Partido Vanguardia Popular. San José. Ediciones Perro Azul, 2008: 209-216; idem. Semblanza de luchadores sociales del Partido Vanguardia Popular. San José. Ediciones Estudios Contemporáneos, 2010: 19-28.

Godoy Urrutia, César. "Carlos Luis Fallas, el Gorki de los bananeros". Hombres y pueblos. Santiago. Editora Austral, 1966: 101-103.
Gudmundson, Lowell. "Fallas Sibaja, Carlos Luis". Tenenbaum, Barbara A. y Dorn, Georgette M. (eds.). Encyclopedia of Latin American History and Culture V. II. New York. C. Scribner's Sons, 1996: 538.

León Villalobos, Edwin. Declaración de Benemérito de las Letras Patrias a Carlos Luis Fallas Sibaja (Calufa). San José: Asamblea Legislativa, 1977.

Mora Rodríguez, Arnoldo. "Carlos Luis Fallas, su época y sus luchas. Por Marielos Aguilar. Colección Debate. Ed. Porvenir, San José, 1983”. Anuario de Estudios Centroamericanos 10. San José, 1984: 163-164.

“[¿Quién es Carlos Luis Fallas?]”. Guatemala: Confederación de Trabajadores de Guatemala, $1949^{63}$.

Zamora Picado, Teresita. "Presentación. Calufa ayer, hoy y siempre. Homenaje en el centenario de su nacimiento (1909. 2009)". Revista Comunicación 18. Nro. especial. Cartago, 2009: 3-5.

Zeledón Cartín, Elías. "Carlos Luis Fallas. Premio 1965”. Zeledón Cartín, Elías. Los Premio Magón. San José. Comisión Nacional de Conmemoraciones Históricas, 1992: 85-93.

\section{CRÓNICAS Y TESTIMONIOS}

Aguilar, Marco. "Una tarde con el ladrón de gallinas". Revista Lectores 88. Turrialba. 2009: 4; reimpreso en: Revista Comunicación 18. Nro. especial. Cartago, 2009: 66-67.

Cabal, Antidio. "Medallón de Calufa". Cultura Universitaria 91. Caracas, 1966: 51-54; reimpreso en: Cuadernos Prometeo 6. Heredia, 1978: 5-6.

Contreras Álvarez, Gerardo. "Tremenda impresión (vivencias de un niño cuando conoció a Calufa)". Revista Comunicación 18. Nro. especial. Cartago, 2009: 68-71.

63 La información procede del Anexo 4; no es claro bajo qué formato circuló esa monografía. 
Fallas González, Carlos Luis. "Calufa: padre y hombre ejemplar". Revista Comunicación 18. Nro. especial. Cartago, 2009: 51-55.

Guillén, Nicolás. "Fallas". América sueña y fulgura. La Habana. Letras Cubanas, 1987: $141-144^{64}$.

Gutiérrez Mangel, Joaquín. "Carlos Luis Fallas”. Gutiérrez Mangel, Joaquín. Los azules días. San José. Editorial de la Universidad de Costa Rica, 2000: 187-192.

Meléndez Ibarra, José. La columna liniera. San José: Ediciones Revolución, 1969.

Morera Agüero, Rosibel. "El Calufa que conocí". Revista Comunicación 18. Nro. especial. Cartago, 2009: 63-65.

Morera Cabezas, José Manuel. "Calufa, nuestro vecino". Revista Comunicación 18. Nro. especial. Cartago, 2009: 56-62.

Robles Rivera, Francisco. "La columna liniera: un hombre, dos historias". Revista Comunicación 18. Nro. especial. Cartago, 2009: 77-80.

Ross, Marjorie. "Centenario de Carlos Luis Fallas". Revista Nacional de Cultura 58. San José, 2010: 9-14.

\section{ENTREVISTAS}

Berrocal, Fernando y Chase, Alfonso. "Entrevista a Carlos Luis Fallas". Crátera. Publicación del Ateneo Universitario I (3). San José, 1966: 5-1265.

64 Publicado originalmente en Revista de Granma, 19 de junio de 1966.

65 En algunas referencias, este material aparece como la última entrevista realizada a Fallas, lo cual debería ser considerado con cuidado, debido a que en la documentación respectiva no se consignan las fechas exactas en que Berrocal y Chase, así como, Herrera García y Mora V., lo entrevistaron. Supra, Introducción, nota 2.
PRÓLOGOS, PREFACIOS, INTRODUCCIONES Y NOTAS PARA SUS LIBROS, FOLLETOS Y CUENTOS

Álvarez García, Imeldo. "Fallas: una expresión de vida”. Fallas Sibaja, Carlos Luis. Mamita Yunai. La Habana. Arte y Literatura, 1975: 7-14.

Arroyo, Víctor Manuel. "Prólogo". Fallas Sibaja, Carlos Luis. Gentes y gentecillas. San José. Editorial Costa Rica, 1975: 7-12; reimpreso en ediciones posteriores de esta novela.

Arroyo, Víctor Manuel. "Prefacio a esta tercera edición de Gentes y gentecillas". Fallas Sibaja, Carlos Luis. Gentes y gentecillas. San José. Trejos, 1967: 7-9.

Arroyo, Víctor Manuel. "Prólogo". Fallas Sibaja, Carlos Luis. Mamita Yunai. San José. Editorial Principios, 1966: 11-16; reimpresa en ediciones posteriores de esta novela.

Blaho, Vladimír. "Milý čitate". Fallas Sibaja, Carlos Luis. Dobrodružstvo môjho života. Bratislava. Mladé letá, 1977: 262.

¿Bychowska, Helena i Zawanowski, Kazimierz?, "(Sin título)". Fallas Sibaja, Carlos Luis. Skata i inne opowiadania. Warszawa. Czytelnik, 1955: 5.

Comité Central de la Federación de Trabajadores del Atlántico. [Sin título]. Fallas Sibaja, Carlos Luis. El peligro de la dictadura. Las elecciones y la organización sindical. San José. Falcó Hermanos, 1935: 138-139.

Comité de Solidaridad Nacional. "Introducción". Fallas Sibaja, Carlos Luis. Don Bárbaro. San José. Comité de Solidaridad Nacional, 1960: 1.

Dashkevich, Yuri. “у земляков мАРкосА РАмиРесА". ФалЛас, Карлос Луис. Маркос Рамирес: приключения костариканского мальчишки: повесть. Москва, Гос. изд-во детской лит-ры, 1958: 3-8.

Gutiérrez Mangel, Joaquín. "Prólogo". Fallas Sibaja, Carlos Luis. Mamita Yunai. Santiago. Quimantú, 1972: 5-7; reproducido en Fallas Sibaja, Carlos Luis. 
Mamita Yunai. Madrid. Castellote, 1976: 7-9 y en: Imprévue 1. Montpellier, 1988: 133-134.

Herrera García, Adolfo. [Sin título]. Fallas Sibaja, Carlos Luis. Tres cuentos. Contraportada. San José: Editorial Costa Rica, 1967.

János, Benyhe. "Elöszó". Fallas Sibaja, Carlos Luis. Mamita Yunai. Budapest. Új M. Kiadó, 1955: 3-8.

Jaroslav Kuchválek y Pat'ava, Miroslav. "Doslov". Fallas Sibaja, Carlos Luis. Maminka Junaj. Praha, snklhu, Brnenské knihtisk, 1953: 173-175.

Kelin, F. “Предисловие”. Фаллас, Карлос Луис, Мамита Юнай. Москва. Изд-во иностранной литературы, 1952: 3-13.

Leon, Alexandru. "Cuvint Inainte". Fallas Sibaja, Carlos Luis. Mamita Yunai. Bucureşti. Editura de Stat pentru Literatură şi Artă, 1955: 5-15.

León, Carlos Augusto. "Prólogo". Fallas Sibaja, Carlos Luis. Mamita Yunai. México: Fondo de Cultura Popular, 1957, páginas sin numerar; reimpreso bajo el título: "Prólogo de la edición mexicana". Mamita Yunai. La Habana. Editorial Vanguardia Obrera, 1960: 17-23 y como "Carlos Luis Fallas y "Mamita Yunai”". Cultura Universitaria 91. Caracas, 1966: 47-50. Versión francesa: "Préface a l'édition mexicaine". Mamita Yunai (Maman Banane and Co.): roman costaricein. Paris. Les Editeurs Français Réunis, 1964: 15-19.

Menton, Seymour. "Carlos Luis Fallas". El cuento costarricense. México y Lawrence. Ediciones de Andrea y University of Kansas Press, 1964: 115.

Molina Jiménez, Iván. "Introducción. Experiencias y viajes". Fallas Sibaja, Carlos Luis. De mi vida. T. I. Heredia. Editorial Universidad Nacional, 2012: 9-14.

Molina Jiménez, Iván. "Introducción. Investigación y política". Fallas Sibaja, Carlos Luis. De mi vida. T. II. Heredia. Editorial Universidad Nacional, 2012: 9-20.
Molina Jiménez, Iván. "Introducción. La expulsión de un regidor comunista". Fallas Sibaja, Carlos Luis. Cuenta Braña. Heredia. Editorial Universidad Nacional, 2010: 9-20.

Molina Jiménez, Iván. "Un pasado comunista por recuperar. Carmen Lyra y Carlos Luis Fallas en la década de 1930". Lyra, Carmen y Fallas, Carlos Luis. Ensayos políticos. San José. Editorial de la Universidad de Costa Rica, 2000: 9-66.

"Nota editorial". En: Fallas Sibaja, Carlos Luis. Mamita Yunai. San José. Lehmann, 1971: 14; reproducida en ediciones posteriores de esta misma editorial y en: Fallas Sibaja, Carlos Luis. Mamita Yunai. Madrid. Castellote, 1976: 14.

Omari, Donika. "Parathënie". Në hijen $e$ bananeve. Tiranë Shtëpia Botuese. "Naim Frashëri", 1971: 3-8.

Ovares, Flora y Rojas, Margarita. "Carlos Luis Fallas: la aventura de una vida". Fallas Sibaja, Carlos Luis. Obra narrativa. 2 volúmenes. San José, Editorial Costa Rica: 2009. Pp. xi-xxv.

Pacheco, León. "Prólogo". Fallas Sibaja, Carlos Luis. Marcos Ramírez. San José. Lehmann, 1971: 11-18; reimpreso en ediciones posteriores de esta novela.

Paltsenkov, J. y Apananski, I. "Carlos Luis Fallas". Roheline põrgu. Mamita Yunai: romaan. Tallinn. Eesti Riiklik Kirjastus, 1961: 5-8.

Picado Gómez, Manuel. "Introducción". Fallas Sibaja, Carlos Luis. Narrativa de Carlos Luis Fallas 1. Studium Generale Costarricense, 1984: 5-21.

Polimeni, Dante. "Prólogo". Cuadernos Prometeo 6. Heredia, 1978: 4-5.

"Prefazione". Mamita Yunai. Roma. Edizioni di Cultura Sociale, 1955: 5-8.

"Prólogo". En: Fallas Sibaja, Carlos Luis. Mamita Yunai. La Habana. Imprenta Nacional de Cuba, 1961: 7-8.

Saxe Fernández, Eduardo. "Presentación". Cuadernos Prometeo 6. Heredia, 1978: 3.

Saxe Fernández, Eduardo. "Nota preliminar". En: Fallas Sibaja, Carlos Luis. Un mes en 
la China roja. San José. Editorial de la Universidad de Costa Rica, 1977: 3-4.

Szleyen, Zofia. "Od tłumacza". Fallas Sibaja, Carlos Luis. Mateczka Yunai. Warszawa, Czytelnik, 1953: 5-13.

Varela, Alfredo. "Predslov". Fallas Sibaja, Carlos Luis. Mamička Junaj. [Bratislava]. Slovenský spisovatel', 1954: 5-9.

Yates, Donald A. y Dalbor, John B. "The Childhood Reminiscences of Carlos Luis Fallas". Imaginación y fantasía: cuentos de las Américas. New York. Holt, Rinehart y Winston, 1960: 74.

侯浚吉. “譯后記”. Fallas Sibaja, Carlos Luis, 绿地狱. 上海. 新文艺出版社, 1958: 224226.

TESIS

Ávila, Eneida. "Las compañías bananeras en la novelística centroamericana". [Ph. D. Dissertation]. Tulane University, 1959.

Baker, Valeria. "The Banana as Icon: orientalism, violence, and the problem of memory in Fallas's Mamita Yunai, Reyes-Manzo's Photography and the Cultural Imagery". [M. A. Thesis]. Institute of Germanic and Romance Studies, 2009.

Brenes Acuña, Luis Eduardo. "Análisis sociológico de la novela Mi madrina". [Tesis de Licenciatura en Filología]. Universidad de Costa Rica, 1987.

Bustabad Ugalde, Lidia y Guerrero Venegas, Damaris. "La estructura sisificada de la novela Marcos Ramírez, de Carlos Luis Fallas". [Tesis de Licenciatura en Filología]. Universidad de Costa Rica, 1978.

Castro Robles, Guillermo. "Análisis estilístico de Mamita Yunai". [Tesis de Licenciatura en Filología]. Universidad de Costa Rica, 1975.

Fonseca Vargas, Jorge. "Gentes y gentecillas; estudio de una novela". [Tesis de Licenciatura en Letras]. Universidad de Costa Rica, 1963.

Herra Guillén, Carlos Alberto. "Realismo creador de Carlos Luis Fallas". [Thèse 3è cycle]. Besançon, 1979.
Herra Guillén, Carlos Alberto. "Mamita Yunai: una novela autobiográfica". Memoire de Maîtrise. Université de Franche-Comté, 1974.

Hodge, Jessica. "La oposición fragmentada: un análisis de la problemática de identidad en Mamita Yunai de Carlos Luis Fallas". [Thesis]. Harvard University, 1992.

Hundhammer, Florian. "Bananen geschichten: das zentralamerikanische Engagement der United Fruit Company im 20. Jahrhundert und seine Perzeption in der Gegenüberstellung von 'realistischerProtestliteratur' (Mamita Yunai, 1941; Prisión verde, 1950; Viento fuerte, 1949) und sozioökonomischen Sachdokumenten". [Magisterarbeit]. Freie Universität Berlin, 2001.

Jiménez Calderón, Rodrigo. "La novela Marcos Ramírez es una imagen crítica". [Tesis de Licenciatura en Literatura]. Universidad Nacional, 1976.

Jiménez Vásquez, Fidelina. "Una lectura histórico-social de la novela Marcos Ramírez". [Tesis de Licenciatura en Filología]. Universidad de Costa Rica, 1993.

Kuhlmann, Ursula. "Literatur und Gesellschaft in Mittelamerika: interpretation des Romans Mamita Yunai von Carlos Luis Fallas als Soziale Praxis". [Magosterarbeit]. Freie Universität Berlin, 1981.

López, Minerva G. "El orgullo contra el determinismo en las obras de Carlos Luis Fallas". M. A. Dissertation, University of Texas at El Paso, 1970.

Luarca Saballos, Lydia. "Gentes y gentecillas, una novela moderna en la década del 40". [Tesis de Licenciatura en Filología]. Universidad de Costa Rica, 1977.

Malo, Lyne. "Mamita Yunai de Carlos Luis Fallas: a la frontera del realismo social $y$ del testimonio". [M. A. Thèse M. A.]. Université de Montréal, 1997.

Miranda Hevia, Gladys Alicia. "Rasgos del relato moderno en Mamita Yunai". [Tesis de Licenciatura en Letras]. Universidad de Costa Rica, 1976. 
Pancrazi, Laetitia. "L'écriture de l'engagement dans Mamita Yunai de Carlos Luis Fallas: de la manchette à la plume". D.E.A. Université Bordeaux 3, 2001.

Powell Benard, Lorein. "Lectura (en crisis) de tres obras racistas". [Tesis de Licenciatura en Literatura]. Universidad Nacional, 1985.

Rojas Pérez, Walter. “¿Desarrollo sustentable? Consideraciones en torno a tres novelas costarricenses de tema medioambiental: Mamita Yunai, La loca de Gandoca y Única mirando al mar". Ph. D. Dissertation, University of Utah, 2005.

Sabatini López-Calleja, Mario. "El taller de Carlos Luis Fallas: una propuesta escenográfica". [Tesis de Licenciatura en Teatro]. Universidad Nacional, 1993.

Vega Ramírez, Francisco. "Perspectivas narrativas sobre el tema del banano en tres obras costarricenses". [Tesis de Licenciatura en Literatura]. Universidad Nacional, 1998.

LIBROS, CAPÍTULOS Y ARTÍCULOS EN REVISTAS ACADÉMICAS Y CULTURALES

Acuña Ortega, Víctor Hugo. "Mamita Yunai: un cuarto de siglo después". Revista Comunicación 18. Nro. especial. Cartago, 2009: 39-46.

A. F. C. "Gentes y gentecillas por Carlos Luis Fallas". Revista de la Universidad de Costa Rica 2. San José, 1947: 175-177.

Arias Mora, Dennis. "La odisea del 'extranjero pernicioso': cuestión heroica $y$ horizontes afectivos en el antifascismo comunista". A Contracorriente. Una Revista de Historia Social y Literatura de América Latina 8 (2). Winter, 2011: 311-321.

Barahona Jiménez, Luis. "Gentes y gentecillas una novela auténticamente nacional". Ensayos. San José, Ministerio de Cultura, Juventud y Deportes, 1985: 51-70.

Barahona Jiménez, Luis. "La picaresca clásica en Marcos Ramírez". Ensayos. San José, Ministerio de Cultura, Juventud y Deportes, 1985: 37-50.
Barrantes Araya, Trino. "La historia se teje en múltiples formas". Revista Estudios 23. San José, 2010: 267-270.

Campa, Annunziata. "Mamita Yunai e l'impegno sociale di Carlos Luis Fallas". Studi di Letteratura Ispano-americana 8. Milano, 1978: 131-141.

Carballo, María Elena. "Fallas, Carlos Luis". Diccionario enciclopédico de las Letras de América Latina, t. II. Caracas. Biblioteca Ayacucho, 1995: 1719-1722.

Carballo, María Elena. "Mamita Yunai". Cilampa 3. Heredia,1983: 15-18.

Castro H., Guillermo. "Volver a leer Mamita Yunai". Casa de las Américas 16 (96). La Habana, 1976: 130-135.

Castro Robles, Guillermo. "Mamita Yunai: una novela hispanoamericana". Kánina. Revista de Artes y Letras de la Universidad de Costa Rica I (1). San José, 1977: 7-13.

Chen Sham, Jorge. "Representación de la infancia y superación del origen ominoso en Marcos Ramírez". Kánina. Revista de Artes y Letras de la Universidad de Costa Rica 34 (2). San José, 2010: 11-16.

Corrales Arias, Adriano. "Presencia de Carlos Luis Fallas Sibaja”. Revista Comunicación 18. Nro. especial. Cartago, 2009: 72-76.

Cuvardic García, Dorde. "Procedimientos enunciativos de la autobiografía ficticia en Mi madrina y de la novela autobiográfica en Marcos Ramírez". Kánina. Revista de Artes y Letras de la Universidad de Costa Rica 34 (2). San José, 2010: 17-26.

Durán Luzio, Juan. "Mamita Yunai en su contexto continental". Cilampa 3. Heredia, 1983: 11-14.

Fonseca Vargas, Jorge. "Cuadro de una zona en una novela de Carlos Luis Fallas". Revista de la Universidad de Costa Rica 29. San José, 1970: 217-222.

Gaínza, Gastón. "Notas para una lectura semiótica de Mamita Yunai". Annales de l'Université d'Abidjan. Serie D, Lettres XVII (1). Côte d'Ivoire, 1984: 27-48. 
García Albero, Javier. "La recepción de Mamita Yunai de Carlos Luis Fallas en Italia y Francia: entre la proximidad lingüística y la divergencia cultural". Letras 43. Heredia, 2008: 193-205.

González Picado, Jézer. Análisis estilístico de Mamita Yunai: homenaje de la APSE a Carlos Luis Fallas (1909-1966). San José: APSE, 2002.

Gouda-Gnaore, Victor. "Récurrence et signification dans Mamita Yunai: de l'immanence textuelle à la transcendance sociale". Impréuue 1. Montpellier, 1988: 101-132.

Grinberg Pla, Valeria y Mackenbach, Werner. "Banana novel revis(it)ed: etnia, género y espacio en la novela bananera centroamericana. El caso de Mamita Yunai". Iberoamericana 23. 2006: 161-178.

Guennec, Mariannick. "Carlos Luis Fallas: les relations conflictuelles entre politique et roman". Le roman au risque de la politique: que peut la littérature? Durand-Le Guern, Isabelle y Galleron, Ioana (eds.). Rennes. Presses Universitaires de Rennes, 2010: 221-234.

Guevara de la Serna, Ernesto (Ché). "Mamita Yunai, de Carlos Luis Fallas". Revista Casa de las Américas 184. La Habana, 1991: 27-28; reimpresa en: Guevara, Ernesto (Ché). Sobre literatura y arte. La Habana. Arte y Literatura, 1997: 54-55. Ariet García, María del Carmen (ed.). América Latina: despertar de un continente. Melbourne. Ocean Press, 2002: 108-109. La Jiribilla. La Habana, 6-12 de octubre de 2007. En: <http://www.lajiribilla.cu/2007/ n335_10/335_10.html $>^{66}$.

Herra Guillén, Carlos Alberto67. "Le réalismecréateur de Carlos Luis Fallas". Cahiers du Monde Hispanique et Luso-brésilien 35. 1980: 248-250.

Herrera, Fernando. "Arquitectura de una novela política”. Revista Comunicación 18. Nro. especial. Cartago, 2009: 12-21.

$66 \quad$ La reseña probablemente fue escrita en la década de 1960. Del libro de Ariet García, hay varias ediciones en español (2002, 2004, 2005 y 2007) y una versión en inglés (2004).
Jones, Sonia. "Restructuración de Mamita Yunai a partir de la manipulación textual". Káñina. Revista de Artes y Letras de la Universidad de Costa Rica 34 (2). San José, 2010: 27-35.

López Avendaño, Gladys. "Mi madrina de Carlos Luis Fallas”. Cilampa 3. Heredia, 1983: 23-26.

Luarca Saballos, Lydia. "La voz: el código ético e ideológico y la complejidad del discurso novelesco, rasgos de modernidad en Gentes y gentecillas". Memoria del Primer Congreso Nacional de Filología, Lingüística y Literatura. San José. Oficina de Publicaciones de la Universidad de Costa Rica, 1986: 221-224.

Luarca Saballos, Lydia. "La voz: la ruptura de la linealidad, las metáforas temporales y los relatos metadiegéticos, signos de modernidad en Gentes y gentecillas". Memoria del Primer Congreso Nacional de Filología, Lingüística y Literatura. San José. Oficina de Publicaciones de la Universidad de Costa Rica, 1986: 215-220.

Mackenbach, Werner. "Banana Novel Revisited: Mamita Yunai o los límites de la construcción de la nación desde abajo". Kánina. Revista de Artes y Letras de la Universidad de Costa Rica 30 (2). San José, 2006: 129-138.

Martín Ruiz, J. F. "La estrategia territorial de las transnacionales bananeras en Centroamérica: el ejemplo de la UFCO en Costa Rica en la visión de los escritores Carlos Luis Fallas y Joaquín Gutiérrez". Morales Padrón, Francisco (ed.). Actas del XVI Coloquio de Historia CanarioAmericana. Las Palmas de Gran Canaria. Ediciones del Cabildo de Gran Canaria, 2006: 81-101.

Martínez, María. "Herencia cultural y colonialidad del poder: un enfoque desde Mamita Yunai". Herencia 22 (2). San José, 2009: 49-56.

Mauro V., María del Carmen. "El caserío del otro lado". Revista Comunicación 18. Nro. especial. Cartago, 2009: 35-38.

Miranda Hevia, Gladys Alicia. "La modernidad de Mamita Yunai”. Olero 23 (3).1977: 186-188. 
Montero Rodríguez, Shirley. "El discurso de la inocencia en Mi madrina de Carlos Luis Fallas". Kánina. Revista de Artes y Letras de la Universidad de Costa Rica 34 (2). San José, 2010: 37-41.

Mora Escalante, Sonia Marta. "Calufa, la crítica y Mamita Yunai”. Cilampa 3. Heredia, 1983: 19-22.

Mora Rodríguez, Arnoldo. "Calufa y el realismo social". Revista Comunicación 18. Nro. especial. Cartago, 2009: 6-11.

Murillo Rojas, Marielos. "Análisis morfológico $y$ enseñanza del vocabulario en la educación primaria”. Káñina. Revista de Artes y Letras de la Universidad de Costa Rica 34 (2). San José, 2010: 137-150.

Ortega Figueroa, Humberto. "Carlos Luis Fallas Sibaja: Mamita Yunai". González Villanueva, Gustavo (coord.). Escritores latinoamericanos. Estudio y comentarios: leo-pienso-opino. San José. Promesa, 2008: 11-26.

Ortiz, María Salvadora. "Mamita Yunai: novela de la plantación bananera". Káñina. Revista de Artes y Letras de la Universidad de Costa Rica 16 (1). San José, 1992: 9-17.

Pacheco, León. "Marcos Ramírez: un libro único". Boletín Literario 15. San José, 1985: 4-7.

Picado Sotela, Isabel. "Mamita Yunai: literatura de protesta social en la novela de Carlos Luis Fallas". Tiempo Actual 5 (20). San José, 1981: 59-74.

Picado Gómez, Manuel. "Carlos Luis Fallas: visión de conjunto". Revista Iberoamericana LIII (138-139). 1987: 219231.

Picado Gómez, Manuel. "Ejercicio de lectura: Marcos Ramírez". Káñina. Revista de Artes y Letras de la Universidad de Costa Rica 10. San José, 1981: 79-102.

Prieto, Emilia. "Gentes y gentecillas por Carlos Luis Fallas". Escritos y grabados. San José. Ministerio de Cultura, Juventud y Deportes, 1977: 275-286 ${ }^{68}$.

68 Publicado originalmente en Repertorio Americano (1947).
Riccio, Alessandra. "Mamita Yunai e Pedro Arnáez: dueideologie a confronto". Napoli 18 (1). Annalidell'Istituto Universitario Orientale, Sezione Romanza, 1976: 137-143.

Rodríguez Cascante, Francisco. "Escribir con compromiso: la generación del 40". Kánina. Revista de Artes y Letras de la Universidad de Costa Rica XxxI (2). San José, 2007: 227-236.

Rojas Pérez, Walter. Costa Rica violada: el caso de Mamita Yunai. San José: Editorial Porvenir, 2006.

Salas Zamora, Edwin. "La perspectiva y otros aspectos de Gentes y gentecillas de Carlos Luis Fallas". Repertorio Americano 7 (3). Heredia, 1981: 11-13.

Sánchez Mora, Alexánder. "Las múltiples lenguas de Calufa". Káñina. Revista de Artes y Letras de la Universidad de Costa Rica 34 (2). San José, 2010: 43-46.

Saxe Fernández, Eduardo. "Imágenes de la violencia intra masculina en Costa Rica: el caso de Marcos Ramírez de Carlos Luis Fallas". Revista Comunicación 18. Nro. especial. Cartago, 2009: 29-34.

Solera, Rodrigo. "Carlos Luis Fallas: el novelista de su propia vida". Hispania 53 (3). Septiembre 1970: 403-410.

Tomcsányi, Judit. "Mamita Yunai: una traducción al húngaro". Letras 46. Heredia, 2009: 69-85.

Valembois, Víctor. "El mundo, también un pañuelo literario. Dos novelas antiimperialistas, una comparación". Káñina. Revista de Artes y Letras de la Universidad de Costa Rica XxxI (2). San José, 2007: 265-272.

Valero, Pino. "La traducción alemana de Marcos Ramírez, de Carlos Luis Fallas". Letras 48. Heredia, 2008: 157-175.

Vargas Vargas, José Ángel. "Marcos Ramírez y su dimensión histórico social". Revista Comunicación 8 (2). Cartago, 1995: 5-10.

Vargas Vargas, José Ángel. "Para una comparación entre Las aventuras de Tom Sawyer y Marcos Ramírez". Kánina. Revista de Artes y Letras de la Universidad de Costa Rica 19 (2). San José, 1995: 69-75. 
Vega C., Miguel A. "Recepción y traducción en alemán de Mamita Yunai, de Carlos Luis Fallas". Letras 43. Heredia, 2008: 143-156.

Zúñiga Rivera, Mónica. "El taller como espacio de transformación del mundo". Revista Comunicación 18. Nro. especial. Cartago, 2009: 22-28.

白方濟. El chino en Mamita Yunai de Carlos Luis Fallas. Tamsui. Departamento de Español de la Universidad de Tamkang, 2006:1-18.

\section{BIBLIOGRAFÍAS}

"Bibliografía crítica selectiva sobre Carlos Luis Fallas". Cilampa 3. Heredia, 1983: 4-10.

Fernández, Víctor Hugo. "Notas para una bibliografía circunstancial de Carlos Luis Fallas Sibaja”. Inter-c-a-mbio. Revista sobre Centroamérica y el Caribe 9. San José, 2012: 10. En prensa.

Quesada Soto, Álvaro. "Carlos Luis Fallas". Quesada Soto, Álvaro. Rutas de subversión. La novela de los años cuarenta. Estudios sobre dramaturgia. Bibliografía general sobre crítica de la literatura costarricense 1890-2000. San José. Editorial de la Universidad de Costa Rica, 2010: 26-29.

Ramírez Hidalgo, Maricela. "Biobibliografía Carlos Luis Fallas Sibaja 1909-1966”. San José: Universidad de Costa Rica, 2010.

Zúñiga Arias, Jeffrey. "Biobibliografía sobre 'Calufa'. Carlos Luis Fallas”. San José: Universidad de Costa Rica, 1997.

\section{ADAPTACIONES DE OBRAS DE FALLAS}

"Calufa vive: cuentos y canciones". San José: Ministerio de Cultura y Juventud, 2011 (fragmentos de novelas y cuentos de Fallas escenificados por Rodolfo González Ulloa y Wilson Arroyo, dirección de Juan Madrigal).

"El taller". Heredia: Escuela de Arte Escénico, Universidad Nacional, 1991 (dirección Remberto Chaves).
"Marcos Ramírez". San José: SINART, 1980 (trece episodios televisivos, dirección de Santiago Herrera).

"Mi madrina". San José: Compañía Nacional de Teatro, 1978 (dirección de Alfredo Catania); Cartago: Colegio Universitario de Cartago, ¿1991-1992? (dirección de Rodrigo Muñoz Azofeifa).

\section{ENTIDADES Y ORGANIZACIONES NOMBRADAS} EN HOMENAJE A FALLAS

Brigada Calufa (formada por integrantes del Partido Vanguardia Popular para apoyar a los sandinistas). San José, ¿1979?

Calufa por Media Calle (grupo de zanqueros del barrio El Llano). Alajuela, ¿2003?

Colegio Profesional Nocturno Carlos Luis Fallas Sibaja. Alajuela, 1979-1982 ${ }^{69}$.

Grupo Cultural, Ambiental y Resistencia CALUFA. Alajuela, ¿200770?

Teatro Calufa (grupo teatral de aficionados). San José, ¿1974?

\section{FICCIONALIZACIÓN DE FALLAS Y SUS OBRAS}

Díaz Arias, David. "Los señores de piedra". Molina Jiménez, Iván et ál. Marte inesperado. San José: Grupo Nación, 2012: 63-74.

Grupo Tierranegra. "1934”. San José: Grupo Tierranegra, 1977 (dirección de Luis Carlos Vásquez).

"La columna liniera". Libertad. 9 de enero- 6 de marzo de 1971 (textos de José Meléndez Ibarra, dibujos de Cora Franchini).

Molina Jiménez, Iván. "Sputnik". Casasa Núñez, Laura et ál. Posibles futuros. Cuentos de ciencia ficción. San José. Editorial Universidad Estatal a Distancia, 2009: 49-60.

69 El colegio se fundó en 1979 y fue nombrado en recuerdo de Fallas en 1982.

70 También conocido como Grupo Cultural Calufa o Colectivo Calufa. 
Molina Jiménez, Iván. "Première". Molina Jiménez, Iván. La miel de los mudos y otros cuentos ticos de ciencia ficción. San José. Editorama, 2003: 77-81.
OTROS

"Colección de fotografías: Carlos Luis Fallas". San José: s. e., 1991.

Fuente: la misma del Anexo 1. Quesada Soto, Álvaro. "Carlos Luis Fallas". Quesada Soto, Álvaro. Rutas de subversión. La novela de los años cuarenta. Estudios sobre dramaturgia. Bibliografía general sobre crítica de la literatura costarricense 1890-2000. San José. Editorial de la Universidad de Costa Rica, 2010: 26-29 y Ramírez Hidalgo, Maricela. "Biobibliografía Carlos Luis Fallas Sibaja 1909-1966". San José: Universidad de Costa Rica, 2010. 


\section{ANEXO 3}

\section{CRONOLOGÍA DE}

CARLOS LUIS FALLAS

1909-01-21: nace en la ciudad de San José; luego se traslada a vivir a Alajuela.

1916: inicia sus estudios primarios.

1921: se une a las tropas que van a Coto, durante el conflicto limítrofe entre Costa Rica y Panamá.

1922: inicia sus estudios secundarios en el Instituto de Alajuela.

1923: abandona el colegio y labora como aprendiz en los talleres del Ferrocarril al Pacífico.

1925: se va a trabajar como liniero al Caribe costarricense.

1931: regresa a Alajuela, aprende el oficio de zapatero y se integra a la sección alajuelense del Partido Comunista de Costa Rica (fundado en junio); muere su madre, Adelina Fallas Sibaja.

1932-07-11: tiene un enfrentamiento público con el Comandante de Plaza de Alajuela, por lo cual es acusado de haber injuriado a los secretarios del Congreso.

1933-05-01: participa en las actividades del Primero de Mayo organizadas por el Partido Comunista en San José.

1933-05-22: herido en el choque entre desocupados y la policía, ocurrido en San José.

1933-06-23: condenado a un año, un mes y un día de destierro por las supuestas injurias a los secretarios del Congreso; escoge ser confinado en Limón.

1933-10-22: el primer artículo periodístico, en que se le reconoce como autor, es publicado por el semanario Trabajo.

1933-12-10: Trabajo le publica un informe sobre las condiciones laborales de los barreteros empleados por la United Fruit Company.

1934: Secretario General del Comité que dirige la huelga bananera de agosto-septiembre; posteriormente, es encarcelado y se declara en huelga de hambre y es liberado.
1935: publica su primera obra El peligro de la dictadura. Las elecciones y la organización sindical. Es postulado en el tercer lugar de la papeleta comunista para las elecciones legislativas de febrero de 1936 (no fue electo).

1935-08-04: Trabajo le publica un informe resultado de una investigación acerca de los mineros del Desmonte.

1938: en septiembre participa en el Congreso de la Confederación de Trabajadores de América Latina, en México.

1940-02-11: electo regidor por la Municipalidad de San José.

1940: en diciembre, el manuscrito de Mamita Yunai es descalificado por el jurado costarricense $y$ no participa en el concurso para escoger la mejor novela latinoamericana, convocado por la Editorial estadounidense Farrar\&Reinhart.

1941-07-19: publica en Trabajo un comentario de la carta pastoral del arzobispo Víctor Manuel Sanabria que supone un evento de considerable importancia en el proceso de acercamiento, entonces en curso, entre el Partido Comunista y el Gobierno de Rafael Ángel Calderón Guardia.

1941-07-28: el Partido Comunista realiza una actividad para homenajearlo por la publicación de Mamita Yunai.

1942: publica el cuento "La dueña de la guitarra de las conchas de colores" en la antología Escritores de Costa Rica, preparada por Rogelio Sotela.

1944-02-13: electo diputado al Congreso.

1945-12-21: lidera junto con Alfredo Picado la huelga de los trabajadores de la Northern Railway Company.

1946: el manuscrito de Gentes y gentecillas recibe una mención honorífica en los Juegos Florales convocados por la Universidad de Costa Rica.

1947: publica Gentes y gentecillas.

1948-02-08: reelecto diputado al Congreso, pero no desempeña el cargo debido a que el resultado de los comicios legislativos fue desconocido, tras el triunfo de las fuerzas encabezadas por José Figueres en la Guerra Civil de 1948. 
1948: marzo-abril, lidera la llamada columna liniera y lucha en la Guerra Civil.

1948-04-27: acompaña a Manuel Mora durante el trayecto que culmina luego en una reunión con Figueres (Pacto de Ochomogo); no está presente durante ese encuentro.

1948: condenado a cuatro años de cárcel por el robo de 54 gallinas finas.

1949: liberado debido a la fuerte presión nacional e internacional. Mamita Yunai se publica en Chile e inicia su proceso de difusión por América Latina y Europa.

1950: el poema "Calero trabajador del banano" circula en la primera edición del Canto general de Pablo Neruda.

1951: viaja a Europa.

1952: publica Marcos Ramírez.

1954: publica Mi madrina y los relatos "El taller" y "Barreteros" en un mismo volumen. Viaja a la Unión Soviética por razones médicas. En México circula su folleto Reseña de la penetración e intervención yanqui en Centroamérica.

1955: publica La gran huelga bananera del Atlántico, que es incorporada en la edición mexicana de Mamita Yunai (1957).

1956: viaja a China.
1957: publica una pequeña "Autobiografía" en la edición mexicana de Mamita Yunai.

1960: publica Don Bárbaro. Integra, en condición de Tesorero, la Junta Directiva de la Editorial Costa Rica; viaja a Cuba.

1963: la Fundación William Faulkner le otorga un certificado al mérito por Marcos Ramírez, el cual fue dado a conocer en 1963; sin embargo, pese al interés de algunos editores estadounidenses, la novela no se traduce al inglés.

1964: nuevo viaje a la Unión Soviética por razones médicas.

1966: se le otorga el Premio Magón, correspondiente a 1965.

1966-05-07: fallece en San José.

1967: la Editorial Costa Rica publica, en un volumen, Mi madrina y en otro (Tres cuentos) los relatos "La dueña de la guitarra de las conchas de colores", "Barreteros" y "El taller".

1977-11-14: declarado Benemérito de la Patria.

Fecha de ingreso: 02/11/2011

Fecha de aprobación: 05/01/2012

Fuente: Arroyo, Carlos Luis Fallas. Aguilar Hernández, Carlos Luis Fallas. Quirós Vargas, Los tribunales de probidad. Pp. 89-91. López, Juan Diego. Los cuarenta días de 1948. San José. Editorial Costa Rica, 1998: 59-64, 96-97, 177 y 264266. Cuevas Molina, El punto sobre la $i$. P. 97. Cohn, "William Faulkner". Pp. 8 y 11. Víquez Guzmán, Benedicto. "Las generaciones de los novelistas costarricenses". Heredia, 2012: 346. Inédito. 
